\title{
GENETIC ANALYSIS OF ENZYME POLYMORPHISMS IN PLAICE (PLEURONECTES PLATESSA)
}

\author{
C. E. PURDOM and D. THOMPSON \\ Ministry of Agriculture, Fisheries and Food, Fisheries Laboratory, \\ Pakefield Road, Lowestoft \\ and \\ P. R. DANDO \\ Marine Biological Association of the United Kingdom, The Laboratory, \\ Citadel Hill, Plymouth PLI PB2
}

Received 17.ii.76

\section{Summary}

Genetic analysis was performed on five enzyme systems (G3PDH; GPI-A; GPI-B; PGM; MDH-A) in plaice (Pleuronectes platessa) collected in spawning condition from the North Sea. Conventional crosses, induced gynogenesis and induced triploidy were performed. The data conclusively demonstrated the inheritance of isozymes by co-dominant alleles at individual loci for each system. No linkage was observed but tests did not include MDH nor the possibility of linkage between G3PDH and GPI-A. Some anomalous segregation ratios were observed, particularly a deficiency of heterozygotes for GPI-A, but the data were largely in conformity with Mendelian expectations. At the PGM locus, five independent anomalous individuals were scored and interpreted as mutations with a mutation rate of $1 \cdot 1 \times 10^{-3}$ per gamete. Recombination with the centromere was assessed and induced triploidy and cross-over values of 41 per cent for PGM, 19 per cent for MDH-A and 9 per cent for GPI-B were derived on the assumption of complete interference. Amongst the parent fish, genotypic and phenotypic frequencies were largely consistent with the expectations of the Hardy-Weinberg Law, and allelic frequencies were not significantly different between year of collection or location of collection ground.

\section{INTRODUGTION}

ElEGTROPHORETIC analysis of protein variation between individuals of a species is a powerful tool in the genetic study of natural populations. In marine fish, such studies have been widely concerned with the identification of stocks in species of commercial importance. The extensive literature in the field has been reviewed by de Ligny (1969).

More recent work has associated different allelic forms of enzymes with varying environmental conditions (Koehn, 1970; Johnson, 1971; Merritt, 1972; Powers and Powers, 1975).

Little attempt has been made to study the formal genetics of marine fish by breeding trials, and genetic interpretation has been by homology with similar systems in mammals and Drosophila and by compliance between observation and hypothesis on the basis of the Hardy-Weinberg Law.

Plaice (Pleuronectes platessa L.) is one of the few marine species of commercial importance which can be bred in captivity. A variety of polymorphic enzymes exist in this species although, as yet, there is no indication that their distributions vary between presumed stocks. This paper reports 
studies on the inheritance of some of these enzyme variants, using conventional Mendelian methods, gynogenesis (Purdom, 1969) and induced triploidy (Purdom, 1972).

The haploid chromosome complement of plaice comprises 24 telecentric chromosomes (Barker, 1972) with an even-size distribution from the smallest to the largest, which is about twice the size of the smallest. The probability of finding linked loci is therefore small, but gynogenesis and induced triploidy supply a way of measuring recombination between single loci and the centromere and hence a method for producing chromosome maps.

\section{Materials AND methods}

Sexually mature plaice were taken by trawl from several grounds in the North Sea. Individual fish were marked by tags or by cold branding. Skeletal muscle samples were taken by needle biopsy and analysed by starch gel electrophoresis for the following enzymes:

Glycerol-3-phosphate dehydrogenase (G3PDH)

International enzyme number

Glucosephosphate isomerase-A (GPI-A)

1.1.1.8

Glucosephosphate isomerase-B (GPI-B)

Phosphoglucomutase (PGM)

NAD-linked supernatant malate dehydrogenase-A

(MDH-A)

NAD-linked supernatant malate dehydrogenase-B

(MDH-B)

Selected parents were crossed by artificial fertilisation. Eggs were incubated at $7^{\circ} \mathrm{C}$ and larvae were either tested immediately upon hatching or were reared in batches of 200 for each cross in 301 tanks with static water at $11^{\circ} \mathrm{C}$. The larvae were fed on a diet of Artemia salina nauplii and killed at or near metamorphosis 8-10 weeks after hatching. In the earlier work, offspring were deep frozen for storage prior to analysis, but better results were obtained latterly by performing electrophoresis on fresh tissues or on fresh whole larvae soon after hatching.

Vertical starch gel electrophoresis as described by Dando (1970) was used for enzyme analysis. For later work on G3PDH and MDH both horizontal and vertical gel electrophoresis was carried out using a $\mathrm{pH} 6 \cdot 95$ N-(3-aminopropyl)-diethanolamine-citric acid buffer (Clayton and Tretiak, 1972) instead of trisborate $\mathrm{pH} 8.7$ buffer. This change in $\mathrm{pH}$ gave greater G3PDH and MDH stability and improved the resolution of the technique. Muscle biopsy samples and larvae were applied directly to slots in the gels.

G3PDH, MDH, PGM and GPI were stained by coupling their reactions to the reduction of the tetrazolium dye 3-(4:5-dimethyl-thiazolyl-2)-2:5diphenyl-monotetrazolium bromide (thiazolyl blue). None of the activity bands developed in the absence of the specific enzyme substrate. Isoenzymes were numbered consecutively, on the basis of electrophoretic mobility, with the lowest number given to the form with the highest mobility towards the anode. 
Gynogenesis was performed by the fertilisation of eggs with irradiated plaice spermatozoa, or with halibut (Hippoglossus hippoglossus) spermatozoa. Fertilisation was performed at approximately $7^{\circ} \mathrm{C}$ and after 15 minutes the eggs were subjected to a cold shock by instant immersion in sea water at less than $0^{\circ} \mathrm{C}$. Eggs were held at a temperature of $0^{\circ} \mathrm{C}$ for 2-3 hours, after which a gradual return to the normal incubation temperature was permitted. Triploidy was induced in the same way following fertilisation with plaice spermatozoa.

\section{Results}

Table 1 lists the phenotypes of fish which comprised the parental pool during the 1972-75 seasons. Application of the Hardy-Weinberg Law gave no evidence of disparity between allelic and genotypic frequencies

TABLE 1

Distribution of phenotypes in fish collected from the North Sea

\begin{tabular}{|c|c|c|c|c|c|}
\hline Phenotype & G3PDH & GPI-A & GPI-B & PGM & MDH-A \\
\hline $1-1$ & 2 & 1 & - & - & - \\
\hline $2-2$ & 162 & 182 & - & 1 & 81 \\
\hline $3-3$ & 1 & - & - & 25 & 2 \\
\hline $4-4$ & 1 & - & 1 & 67 & - \\
\hline $1-2$ & 10 & 13 & - & - & - \\
\hline $1-3$ & 1 & - & - & 2 & - \\
\hline $1-4$ & - & - & - & 4 & - \\
\hline $2-3$ & 9 & 5 & - & 1 & 25 \\
\hline $2-4$ & 1 & - & - & 2 & - \\
\hline $2-6$ & - & - & 3 & - & - \\
\hline $3-4$ & - & - & - & 97 & - \\
\hline $3-5$ & - & - & - & 1 & - \\
\hline $4-5$ & - & - & - & 2 & - \\
\hline $4-6$ & - & - & 18 & - & - \\
\hline $6-6$ & - & - & 171 & - & - \\
\hline 6-7 & - & - & 9 & - & - \\
\hline Untyped & 18 & 4 & 3 & 3 & - \\
\hline
\end{tabular}

except for an excess of homozygotes at the G3PDH locus $\left(\chi^{2}=3.97\right.$ : $\mathrm{P}=0 \cdot 05)$.* However, 9 per cent of the fish were untyped for this enzyme for technical reasons. Table 2 lists the major allele frequencies for each enzyme system against collection ground and year. There were no significant differences between samples with respect to individual loci.

\section{(i) Conventional crosses}

In over 70 crosses performed during the 1972-75 spawning seasons, the enzyme variants were predominantly transmitted in accordance with the simple hypothesis that they were determined by co-dominant alleles at individual loci for each system. In all crosses between a homozygote and a heterozygote the offspring segregated into only two classes. Single phenotypes are therefore assumed to be homozygotes for the alleles in question.

* This excess could be due to the presence of null alleles in the population rather than to the Wahlund effect or differential mortality. 
TABLE 2

Allele distribution by year and fishing ground

\begin{tabular}{|c|c|c|c|c|c|c|c|c|c|c|c|}
\hline \multicolumn{2}{|l|}{ Locus } & \multicolumn{2}{|c|}{ G3PDH } & \multicolumn{2}{|c|}{ GPI-A } & \multicolumn{2}{|c|}{ GPI-B } & \multicolumn{2}{|c|}{ PGM } & \multicolumn{2}{|c|}{ MDH-A } \\
\hline Allele ground & Year & 2 & Others & 2 & Others & 6 & Others & 4 & Others & 2 & Others \\
\hline Silver Pits & 1974 & 48 & 2 & 47 & 3 & 50 & - & 24 & 26 & 44 & 6 \\
\hline Tea Kettle & 1973 & 97 & 13 & 120 & 4 & 117 & 9 & 71 & 55 & - & - \\
\hline & 1974 & 44 & 4 & 47 & 1 & 42 & 6 & 30 & 18 & 43 & 5 \\
\hline West Mud Holes & 1975 & 85 & 3 & 84 & 4 & 79 & 9 & 58 & 30 & 72 & 16 \\
\hline Other Grounds & 1972 & 35 & 3 & 41 & 5 & 43 & 3 & 30 & 16 & - & - \\
\hline & 1973 & 10 & 2 & 16 & - & 16 & - & 11 & 5 & - & - \\
\hline & 1974 & 25 & 3 & 27 & 3 & 25 & 5 & 15 & 15 & 28 & 2 \\
\hline Totals & & 344 & 30 & 382 & 20 & 372 & 32 & 239 & 165 & 187 & 29 \\
\hline$\%$ others & & & $8 \cdot 0$ & & $5 \cdot 0$ & & $7 \cdot 9$ & & $40 \cdot 8$ & & $13 \cdot 4$ \\
\hline
\end{tabular}

Anomalies fell into two categories:

(a) Unexpected segregation which could be explained on the basis of mistyping of one parent or misreading of a parental tag. The results in these cases were consistent with a simple Mendelian model of inheritance providing assumptions were made about the parental genotypes. They will not be further discussed.

(b) Anomalies of segregation ratios or the appearance of individual genotypes which cannot be explained by mis-identification of parents.

\section{(a) Glycerol-3-phosphate dehydrogenase}

Teleosts have three loci coding for different subunits of this enzyme (Numachi, 1971; Engel, Schmidtke and Wolf, 1971; Glayton, Franzin and Tretiak, 1973). The nomenclature of the different G3PDH enzymes is confused and, in the absence of comparative kinetic or immunological data, the identity of the enzyme under discussion with any of the G3PDH enzymes found in these other teleosts cannot be defined. Two loci are known in plaice ( $R$. Ward, pers. comm.) but only one is found in white skeletal muscle. This gives a simple zymogram pattern of a single band in homozygotes and three bands in heterozygotes. This pattern has been described for another flatfish, Lepidorhombus whiff-iagonis (Walbaum), by Dando (1970).

In this study G3PDH proved to be the most difficult enzyme to identify. Weak reactions were observed in much of the frozen material, particularly in 1973, but the use of the $\mathrm{pH} 6.95$ buffer in 1974 gave stronger staining and better resolution.

Table 3 lists the results of crosses involving heterozygotes. Segregation was normal in all cases except the second and third crosses where significant deficiencies of heterozygotes were indicated. $\left(\chi^{2}=5 \cdot 4, \mathrm{P}=0.02\right.$ and $\chi^{2}=6.8 ; \mathrm{P}=0.01$ respectively). This could be attributed to the greater difficulty of scoring the weaker staining heterozygotes. Similar crosses in 1974 gave expected results. In 1972 and 1974419 offspring from 2-2 $\times 2$-2 crosses were also tested. All offspring were homozygous type 2-2. No anomalous phenotypes were observed in the total of 747 offspring examined. 
(b) Glucosephosphate isomerase

Polymorphism for this enzyme in plaice has been described by Dando (1974). The enzyme is controlled by two loci, both forms being detectable in white muscle, and easily separated by electrophoretic mobility; GPI-A having the greatest mobility.

GPI-A: Seven crosses between a homozygote 2-2 and heterozygote 1-2 were performed in 1972 (table 4) and the offspring totalled 171 2-2, 118 1-2

TABLE 3

Segregation of G3PDH alleles

$\begin{array}{ccccccc}\text { Cross* } & \text { Year } & 1-1 & 2-2 & 1-2 & 2-3 & \begin{array}{c}\text { Not } \\ \text { typed }\end{array} \\ 1-2 \times 2-2 & 1972 & - & 20 & 17 & - & - \\ 2-3 \times 2-2 & 1972 & - & 35 & - & 18 & 5 \\ 1-2 \times 1-2 & 1973 & 16 & 17 & 15 & - & 67 \\ 2-2 \times 2-3 & 1973 & - & 8 & -6 & - & 83 \\ 1-2 \times 1-2 & 1974 & 32 & 35 & 66 & - & 4 \\ 1-3 \times 2-2 & 1974 & - & - & 9 & - & - \\ 2-2 \times 1-2 & 1974 & - & 12 & 10 & - & \end{array}$

TABLE 4

Offspring segregation in crosses between fish homozygous for allele 2 and heterozygous for alleles 1-2 (in brackets) for GP1-A, performed during 1972

\begin{tabular}{|c|c|}
\hline \multicolumn{2}{|c|}{ Parents } \\
\hline$(7076) *$ & 7064 \\
\hline 7075 & $(7070)$ \\
\hline (7073) & 7074 \\
\hline (7068) & 7064 \\
\hline (7076) & 7069 \\
\hline$(7076)$ & 7080 \\
\hline$(7076)$ & 7084 \\
\hline
\end{tabular}

Total

$\begin{array}{rr}2-2 & 1-2 \\ 25 & 29 \\ 22 & 12 \\ 21 & 5 \\ 21 & 16 \\ 35 & 23 \\ 44 & 31 \\ 3 & 2 \\ 171 & 118\end{array}$

* Lowestoft identification numbers.

with a highly significant deficiency in heterozygotes $\left(\chi^{2}=9 \cdot 7 ; \mathrm{P}=0.001\right)$. Two similar crosses performed in 1974, however, produced totals of $1002-2$ and 101 1-2 individuals. The deficiency of the 1-2 genotype tended to occur in crosses with low survival. The data are therefore consistent with an hypothesis that the 1-2 genotype is less fit than the 2-2 genotype under adverse conditions although there is no corroborative evidence to support this. A 1975 cross between 2-2 and 2-3 produced a normal segregation of 32 2-2:28 2-3; and in a cross involving two heterozygous parents a normal segregation of $61-1: 52-2$ and 12 1-2 was observed. A total of 1883 offspring from $2-2 \times 2-2$ crosses were also tested. All the offspring were of homozygous type 2-2 except for one type 2-1, found in 1974. This allele has not been previously described and migrates faster than allele 1 . As allele l was not present in the 1974 parent gene pool this abnormality cannot be the result of sample contamination. 
GPI-B: Four alleles were examined. Table 5 lists the segregation ratios in 15 crosses between 6-6 homozygotes and the three heterozygotes. No significant departures from an expected 1:1 ratio were observed either in individual crosses or pooled totals for crosses of particular genotypes. In two crosses with $2-6 \times 6-7$ parents the total progeny were $186-6 ; 262-6$; $206-7 ; 19$ 2-7 and in one cross 4-6 6 6-7 there were 6 6-6 and two each of 4-6, 6-7 and 4-7 with no significant departure from expectation. In one cross 4-6 $64-6$ the offspring numbered $44-4 ; 106-6 ; 74-6$; the deviation from an expected $1: 2: 1$ segregation was borderline $\left(\chi^{2}=5 \cdot 76 ; \mathrm{P}=0.05\right)$, but in view of the number of crosses tested, was not considered significant. Offspring from 6-6 $\times$ 6-6 crosses numbered 876 and all were homozygous.

TABLE 5

Segregation of GPI-B alleles

$\begin{array}{cccccccc}\text { Cross } & \text { No. of } & & & & & \\ 6-6 \times 2-6 & 2 & 288 & 256 & - & - & \chi^{2} & P \\ 6-6 \times 4-88 & 0 \cdot 15 \\ 6-6 \times 4-6 & 8 & 174 & - & 149 & - & 1.93 & 0.15 \\ 6-6 \times 6-7 & 5 & 97 & - & - & 120 & 2 \cdot 44 & 0 \cdot 10 \\ \text { Totals } & 15 & 559 & & 525 & & 1.07 & 0.25\end{array}$

\section{(c) Phosphoglucomutase}

Plaice has two separate zones in PGM activity on zymograms of tissue extracts. The most anodal zone is found only in erythrocyte extracts. The second zone is present in all other tissues, including skeletal muscle, and consists of two or four bands, in presumed homozygotes and heterozygotes respectively.

The results of crosses involving five alleles at the PGM locus are listed in table 6 . Where more than one cross of particular genotypes occurred, and there was no evidence of heterogeneity, the results are pooled. In the majority of cases, segregation ratios were consistent with expectation on the basis of a simple Mendelian mode of inheritance and there was no evidence of selective advantage for particular genotypes. There were several discrepancies.

A noticeable departure from expectation occurred in the first of the 3-4 $\times 1-4$ crosses, with a highly significant deficiency of allele 1 . The full cross was 2-2, 2-2, 6-7, 3-4 ×2-2, 2-2, 2-6, 1-4 in the order G3PDH, GPI-A, GPI-B and PGM. No departure from expectation was observed at the GPI-B locus which segregated $156-6 ; 192-6 ; 162-7 ; 126-7 ;\left(\chi^{2}=1 \cdot 6\right.$; $\mathrm{P}=0.65$ ) and therefore there was no evidence of sample contamination from another cross which would have to involve a parent genotype GPI-B 1-3 with either PGM 3-4 or PGM 4-4-no such genotypes were present in the pool of parental fish. The PGM allele 1 itself, however, showed no abnormal segregation in four other crosses, one of which employed the same genotypes but not the same fish as in the abnormal cross.

A further anomaly in the above cross was the appearance of a PGM 3 phenotype which could represent a mutation to allele 3 or to a null allele.

Possible mutations also occurred in three other crosses, a 4 phenotype was found in a 3-4 $\times 2-3$ cross, a 3 phenotype in a 3-4 $\times 4-4$ cross and a 2-3 phenotype in a $3-4 \times 3-4$ cross. The first cross was also significantly 
deficient of allele 2, but segregation for this cross at the GPI-B locus (parents $4-6 \times 6-6)$ was as expected, 6-6 23; 4-6 $18\left(\chi^{2}=0.61 ; \mathrm{P}=0.42\right)$. The second cross showed no other abnormalities at the PGM locus, nor at the

TABLE 6

Segregation of $P G M$ alleles

Offspring phenotypes

\begin{tabular}{|c|c|c|c|c|c|c|c|c|c|c|c|}
\hline Cross & No. of matings & 3-3 & $1-3$ & $2-3$ & $3-4$ & $3-5$ & $4-4$ & $1-4$ & $2-4$ & $x^{2}$ & $P$ \\
\hline $3-3 \times 3-4$ & 4 & 165 & - & - & 172 & - & - & - & - & $0 \cdot 15$ & $0 \cdot 70$ \\
\hline $3-3 \times 4-5$ & 1 & - & - & - & 30 & 28 & - & - & - & $0 \cdot 1$ & $0 \cdot 75$ \\
\hline $3-4 \times 1-3$ & $\begin{array}{l}1 \\
1 \\
1\end{array}$ & $\begin{array}{r}2 \\
28 \\
20\end{array}$ & $\begin{array}{r}7 \\
34 \\
22\end{array}$ & - & $\begin{array}{r}7 \\
16 \\
16\end{array}$ & - & - & $\begin{array}{r}5 \\
20 \\
20\end{array}$ & - & $\begin{array}{l}3 \cdot 19 \\
7.96 \\
0.97\end{array}$ & $\begin{array}{l}0 \cdot 40 \\
0 \cdot 05 \\
0 \cdot 85\end{array}$ \\
\hline $3-4 \times 1-4$ & $\begin{array}{l}1 \\
1\end{array}$ & (1) & $\begin{array}{r}2 \\
18\end{array}$ & - & $\begin{array}{l}25 \\
18\end{array}$ & - & $\begin{array}{l}24 \\
31\end{array}$ & $\begin{array}{l}10 \\
28\end{array}$ & - & $\begin{array}{r}24 \cdot 00 \\
5 \cdot 80\end{array}$ & $\begin{array}{l}0.0001 \\
0.12\end{array}$ \\
\hline $3-4 \times 2-3$ & $\begin{array}{l}1 \\
1\end{array}$ & $\begin{array}{l}58 \\
14\end{array}$ & - & $\begin{array}{r}50 \\
3\end{array}$ & $\begin{array}{l}43 \\
14\end{array}$ & - & $\overline{(1)}$ & - & $\begin{array}{r}40 \\
7\end{array}$ & $\begin{array}{r}4.04 \\
11.01\end{array}$ & $\begin{array}{l}0 \cdot 25 \\
0 \cdot 01\end{array}$ \\
\hline $3-4 \times 2-4$ & 1 & - & - & 42 & 37 & - & 42 & - & 32 & $1 \cdot 8$ & $0 \cdot 60$ \\
\hline $3-4 \times 3-3$ & 2 & 63 & - & - & 57 & - & - & - & - & $0 \cdot 30$ & $0 \cdot 60$ \\
\hline $3-4 \times 3-4$ & $\begin{array}{l}6 \\
1 \\
1 \\
1 \\
1\end{array}$ & $\begin{array}{l}42 \\
18 \\
19 \\
69 \\
15\end{array}$ & $\begin{array}{l}- \\
E \\
-\end{array}$ & $\begin{array}{l}- \\
\overline{-} \\
(1)\end{array}$ & $\begin{array}{r}101 \\
12 \\
31 \\
48 \\
11\end{array}$ & $\begin{array}{l}- \\
z \\
-\end{array}$ & $\begin{array}{r}36 \\
4 \\
5 \\
8 \\
5\end{array}$ & $\begin{array}{l}- \\
- \\
-\end{array}$ & $\begin{array}{l}- \\
- \\
-\end{array}$ & $\begin{array}{r}3 \cdot 36 \\
14 \cdot 47 \\
8 \cdot 02 \\
66 \cdot 26 \\
9 \cdot 06\end{array}$ & $\begin{array}{l}0 \cdot 20 \\
0 \cdot 0007 \\
0 \cdot 017 \\
0 \cdot 0001 \\
0 \cdot 01\end{array}$ \\
\hline $3-4 \times 4-4$ & $\begin{array}{l}8 \\
1 \\
1 \\
1\end{array}$ & $\begin{array}{l}- \\
\overline{(1)}\end{array}$ & $\begin{array}{l}- \\
-\end{array}$ & $\begin{array}{l}- \\
- \\
-\end{array}$ & $\begin{array}{r}150 \\
37 \\
69 \\
29\end{array}$ & $\begin{array}{l}- \\
- \\
-\end{array}$ & $\begin{array}{r}151 \\
21 \\
44 \\
22\end{array}$ & $\begin{array}{l}- \\
-\end{array}$ & $\begin{array}{l}- \\
-\end{array}$ & $\begin{array}{l}0.003 \\
4 \cdot 41 \\
5 \cdot 53 \\
1.23\end{array}$ & $\begin{array}{l}0.99 \\
0 \cdot 03 \\
0 \cdot 02 \\
0 \cdot 25\end{array}$ \\
\hline $4-4 \times 3-4$ & 3 & - & - & - & 193 & - & 207 & - & - & $0 \cdot 29$ & $0 \cdot 58$ \\
\hline
\end{tabular}

GPI-B locus (parents 6-7 $\times 6-7$; offspring 6-6 11, 7-7 12, 6-7 29; $\chi^{2}=1 \cdot 35$; $\mathrm{P}=0 \cdot 60$ ). The third cross, $3-4 \times 3-4$, was significantly deficient of allele (see table 7), but again segregation at the GPI-B locus was as expected (parents 6-6 $64-6$ offspring 6-6 61; 4-6 65; $\chi^{2}=0.03, P=0.95$ ).

TABLE 7

Segregation of $M D H-A$ alleles

\begin{tabular}{ccrlccc} 
& & \multicolumn{5}{c}{ Offspring phenotypes } \\
\cline { 3 - 6 } Cross & $\begin{array}{c}\text { No. of } \\
\text { matings }\end{array}$ & $2-2$ & $3-3$ & $2-3$ & $\chi^{2}$ & $P$ \\
$2-2 \times 2-3$ & 1 & 58 & - & 55 & $0 \cdot 08$ & $0 \cdot 80$ \\
$2-3 \times 2-2$ & 6 & 182 & - & 175 & $0 \cdot 14$ & $0 \cdot 70$ \\
$2-3 \times 2-3$ & 4 & 29 & 37 & 69 & $1 \cdot 01$ & $0 \cdot 62$
\end{tabular}

Further segregation ratio anomalies occurred in three other $3-4 \times 3-4$ crosses, all showing a deficiency of 4-4 genotypes. Six similar crosses, however, gave expected results. An excess of 3-4 genotypes was observed in two of the $113-4 \times 4-4$ crosses tested. One of these crosses was also heterozygous as the MDH-A locus where segregation was as expected (parents 2-2 $\times 2-3$; offspring 2-2 58, 2-3 55, $\chi^{2}=0.08 ; \mathrm{P}=0.85$ ). 
Offspring from one 3-3 3 3-3 cross and four $4-4 \times 4-4$ crosses comprising 216 individuals were all expected homozygotes.

\section{(d) Malate dehydrogenase}

Only the supernatant form of the enzyme has appreciable activity in plaice white muscle. The zymogram pattern is similar to that described for supernatant $\mathrm{MDH}$ in several other teleosts (Clayton et al., 1971; Wheat et al., 1971; Wheat et al., 1972). In these species two loci code for supernatant MDH subunits in muscle and zymograms show three bands for the enzyme in homozygous individuals, two homodimers and a heterodimer. Variation only occurred in the most anodal form of supernatant $\mathrm{MDH}$ in plaice. The two loci have been designated B and C by Clayton et al. (1971) and A and B by Wheat et al. (1971, 1972). This paper will refer to them as $\mathrm{A}$ and $\mathrm{B}$.

Technical problems with this system were not solved until the 1975 season. Four crosses of the type $2-3 \times 2-3$, six of the type $2-3 \times 2-2$ and one of the type $2-2 \times 2-3$ were performed. The results, in table 7 , are in accordance with expectations.

\section{(e) Linkage}

Many of the crosses which were performed involved heterozygotes at more than one locus. There was no evidence of linkage between any of the pairs of loci listed in table 8 . This table shows the total offspring in

TABLE 8

Complementary segregation class frequencies from crosses between male double heterozygotes at one or both loci

\begin{tabular}{|c|c|}
\hline \multicolumn{2}{|c|}{ Loci } \\
\hline PGM & GPI-B \\
\hline PGM & G3PDH \\
\hline PGM & GPI-A \\
\hline GPI-B & G3PDH \\
\hline GPI-A & GPI-B \\
\hline
\end{tabular}

No. of offspring in complementary segregation

$\overbrace{343}^{2 \text { classes }} \begin{array}{rr}342 \\ 53 & 45 \\ 77 & 89 \\ 41 & 47 \\ 85 & 81\end{array}$

the two complementary segregation classes which arise when one parent is heterozygous at more than one locus and produces four types of gamete, e.g. parent type $2-3,2-3$ produces $2 \cdot 2+3 \cdot 3$ gametes and $2 \cdot 3+3 \cdot 2$ gametes, respectively. There were no significant deviations from an expected $1: 1$ ratio. No tests have yet been made of possible linkage between the $\mathrm{MDH}$ locus and the others, nor between GPI-A and G3PDH.

\section{(f) Individual anomalous FI phenotypes}

Mention has already been made of the appearance of unexpected phenotypes in five independent instances, four at the PGM locus, one at the GPI-A locus. Another instance occurred at the PGM locus, where a 2-4 phenotype was found in a 3-4 $\times 4-4$ triploid cross.

The single nature of these anomalies in broods of $216,39,126,62,52$ and 47 offspring respectively is unlikely to arise by contamination and 
indeed can be eliminated in the first case due to the absence of GPI-A allele 4 in the 1974 stock of potential parents. The simplest interpretation is that they represent mutations.

The total numbers of gametes in which mutation could have been scored for individual alleles at the PGM and GPI-A loci are shown in table 9.

\section{TABLE 9}

Estimated numbers of gametes under test for possible mutations at the PGM and GPI-A loci and numbers of presumed mutations to each allele

\begin{tabular}{rrrrc}
\multicolumn{5}{c}{} \\
\hdashline 1 & 2 & 3 & 4 & 5 \\
6712 & 6656 & 1283 & $1019 \cdot 5$ & 7096 \\
- & 2 & 2 & 1 & - \\
& & & & \\
4683 & - & 5374 & 5464 & - \\
- & - & - & 1 & -
\end{tabular}

The mutation rates expressed as the number of mutations divided by the mean number of tested gametes were $1 \cdot 1 \times 10^{-3}$ mutations per gamete for PGM and $2 \cdot 6 \times 10^{-4}$ mutations per gamete for GPI-A.

\section{(ii) Gynogenesis}

The genotypes of gynogenetic offspring from females heterozygous at three of the enzyme loci are shown in table 10 together with the percentage recombination expressed as the frequency of heterozygous offspring. In

TABLE 10

The genotypes of gynogenetic offspring from individual Po females heterozygous at the loci indicated

\begin{tabular}{|c|c|c|c|c|c|c|c|c|}
\hline & & & Offsp & ig ge & type & & $\%$ rec & nation \\
\hline & $\begin{array}{l}\text { Po genotype } \\
\text { PGM MDH-A }\end{array}$ & $2-2$ & $3-3$ & $4-4$ & $2-3$ & $3-4$ & on both & on one \\
\hline Locus & GPI-B & $4-4$ & $6-6$ & $7-7$ & $4-6$ & $6-7$ & homozygotes & homozygote \\
\hline PGM & & & & & & & & \\
\hline & $3-4$ & - & 6 & $\longrightarrow$ & - & 82 & $93 \cdot 2$ & - \\
\hline & & - & 一 & 1 & - & 7 & $87 \cdot 5$ & - \\
\hline & & - & 一 & - & - & 8 & $100 \cdot 0$ & - \\
\hline & & - & 5 & 12 & - & 45 & $72 \cdot 6$ & $65 \cdot 2$ \\
\hline & & - & 6 & 10 & - & 43 & $72 \cdot 9$ & $68 \cdot 3$ \\
\hline & & 一 & 13 & 19 & - & 139 & $81 \cdot 3$ & 78.5 \\
\hline Totals & & - & 30 & 42 & - & 324 & $81 \cdot 8$ & $79 \cdot 4$ \\
\hline GPI-B & & & & & & & & \\
\hline & $6-7$ & - & 41 & 42 & - & 5 & $5 \cdot 7$ & $5 \cdot 6$ \\
\hline & $4-6$ & 3 & 4 & - & 1 & - & $12 \cdot 5$ & - \\
\hline & & 68 & 129 & - & 59 & - & $23 \cdot 0$ & $18 \cdot 6$ \\
\hline Totals & & 71 & 174 & 42 & & & 18.5 & $15 \cdot 7$ \\
\hline MDH- & & & & & & & & \\
\hline & $2-3$ & 19 & 29 & - & 32 & - & $40 \cdot 0$ & $35 \cdot 6$ \\
\hline & & 51 & 95 & - & 92 & - & $38 \cdot 7$ & $32 \cdot 6$ \\
\hline Totals & & 70 & 124 & - & 124 & - & $39 \cdot 0$ & $33 \cdot 3$ \\
\hline
\end{tabular}


conventional recombination analysis, with pairs of linked loci, one crossover event produces only a single recombined chromosome whereas after diploid gynogenesis, one cross-over between the centromere and a locus produces one recombined chromosome pair in the zygote. In conventional terms, therefore, the observed recombination frequency in gynogenesis is an estimate of twice the map length between the locus and the centromere. The data in table 10 therefore suggest cross-over values of about 41 per cent for PGM, 19 per cent for MDH-A and 9 per cent for GPI-B, all in relation to the centromere which is terminal or sub-terminal in plaice chromosomes.

The recombination values from different females were consistent at the $\mathrm{MDH}$ locus but ranged from 72.6 per cent to 100 per cent at the PGM locus and from 5.7 per cent to 23.0 per cent at the GPI-B locus.

The genotypic arrays in the four larger broods for PGM are significantly different $\left(\chi^{2}=14.04 ; \mathrm{P}=0.007\right)$ and the difference is not only in the frequencies of the heterozygous class but also in the relative frequencies of the two homozygotes. Similar genetic imbalance is shown by the two large broods for GPI-B $\left(\chi^{2}=13.04 ; \mathrm{P}=0.001\right)$ again with a significant difference between the frequencies of the two homozygotes in the larger of the two broods. Although the recombination values at the MDH-A locus were consistent, the second brood tested here also showed a significant difference between the frequencies of the two homozygotes. Normal expectation after gynogenesis would be equal frequencies of the two homozygotes, but this is clearly not the case in these instances. This phenomenon could arise through linkage of lethal or deleterious genes with one or other allele in the heterozygous $\mathrm{P}_{\mathrm{o}}$ female. It might therefore be better to estimate recombination values on the basis of the most common homozygote where there is evidence of disparity between the frequencies of the two homozygotes. Such estimates are included in the final column of table 10 . This, however, does not entirely remove the anomaly for GPI-B where the frequencies of the heterozygotes relative to the most common homozygote still show significant differences between the two large groups of offspring $\left(\chi^{2}=13.07 ; \mathrm{P}=0.001\right)$. A more comprehensive explanation would require the postulation of differing viabilities of the homozygotes within broods and between broods but this is difficult to quantify without backcross or $\mathrm{F}_{2}$ data. The observed recombination in gynogenesis can therefore only give rough estimates of map size. These are all fairly large for the loci studied and multiple crossing-over must also be considered. This will be dealt with in the discussion.

\section{(iii) Induced triploidy}

Many triploid crosses were set up but the majority failed for technical reasons possibly associated with the difficulty of inducing viable triploids in eggs of poor quality. Two successful crosses involving females heterozygous at the MDH locus were also invalid because of the earlier difficulty in scoring $\mathrm{MDH}$ in small fish.

Six progeny were scored from a triploid cross with parents of the G3PDH and PGM genotypes 2-3:4-4×2-2:3-4. For PGM, there were four 4 and two 3-4 phenotypes with low staining for the 3 isozyme in both 3-4 fish. This is consistent with the presumed genotypes 4-4-4 and 3-4-4, but differential staining was not always observed in other triploid material. 
At the G3PDH locus the segregation was two 2, four 2-3 with presumed genotypes 2-2-2 and 2-2-3 or 2-3-3. A preponderance of 2-3 phenotypes would be consistent with a high cross-over frequency between the locus and the centromere, although the data are too few for quantitative assessment. At the PGM locus, a triploid cross of genotypes $3-4 \times 1-4$ produced the following segregation: 4 4-4; $41-3 ; 21-4 ; 73-4 ; 81-3-4$.

The 1-3-4 phenotype was clearly of triploid origin, but differential staining in the other heterozygotes could not be scored. The two crossover classes are 3-3-3 and 1-3-4 and the former could not be distinguished from 3-4. Amongst zygotes with allele 1, the proportion of recombinants was 57 per cent, which is lower than that observed in gynogenesis (80 per cent) but the data are too sparse amongst the triploids for meaningful comparison.

\section{Discussion}

Polymorphism was observed for five enzymes in sexually mature plaice (Pleuronectes platessa) collected from various grounds in the North Sea. The results of crosses between parents of known phenotypes demonstrated conclusively that the polymorphisms were determined by the inheritance of co-dominant alleles at independent loci for each enzyme system.

Amongst the parents, allele frequencies, excluding the commonest allele at each locus, ranged from 0.007 to 0.376 with all but two having low frequencies of 0.05 or less. All the alleles found have also been found in plaice from the Western English Channel and the Irish Sea. There was no evidence of heterogeneity in a comparison of different spawning grounds on the basis of the frequency of the commonest allele at each locus, and on this basis no evidence of genetic isolation of the individual spawning grounds. Samples were small, however, and came predominantly from grounds on the southern edge of the Dogger Bank. Only a few parents were obtained from East Coast or Southern Bight grounds which might conceivably represent populations isolated from the Dogger Bank populations (Simpson, 1959). This possibility is being examined by typing juveniles reared from eggs collected from the different grounds.

The great majority of crosses produced segregation ratios which were consistent with normal Mendelian inheritance in which the different genotypes were of equal fitness. One possible exception to this general rule occurred in the GPI-A system, where there was a significant deficiency of heterozygotes throughout one year and some evidence that this deficiency was related to poor survival conditions. Low survival of heterozygotes for transferrin alleles in tuna has been recorded by Fujino and Kang (1968) and for esterase polymorphism in Zoarces by Christiansen, Frydenberg and Simonsen (1973). Each of these instances occurred under natural conditions, over a longer period of the life-cycle than in the present case and may be alternatively explained by differential migration. There was no lack of GPI-A heterozygotes among parental plaice, but the frequency of allele 1 was low $(0 \cdot 04)$ in relation to the sample size (200) and comparison with results from the hatchery work was inconclusive.

Other anomalies of segregation ratios occurred at the PGM locus, where a significant deficiency of the allele 1 arose in a cross $3-4 \times 1-4$, and an excess of 3-4 and 3-3 genotypes respectively in four separate crosses 3-4 $\times 3-4$. Such anomalies may occur by chance in a large number of crosses. The 
possibility of linked deleterious genes remains but is untestable without recourse to further test generations or to further testing of parents. The latter was not practical since parents were not retained after spawning due to lack of holding facilities.

Single anomalous individuals were observed in six independent crosses and five of these involved the PGM locus. In no case was there any evidence for contamination and the simplest interpretation was that the anomalies arose through mutation. On this basis the estimated mutation rates of $1 \cdot 1 \times 10^{-3}$ mutations per gamete at the PGM locus and $2.6 \times 10^{-4}$ mutations per gamete at the GPI-A locus were extremely high compared with normal spontaneous rates of $10^{-5}$ or less. No mutations were observed at the other three loci studied and estimated values of less than $2.9 \times 10^{-4}, 9.0 \times 10^{-4}$ and $1.4 \times 10^{-3}$ mutations per gamete for the GPI-B, G3PDH and MDH-A loci respectively were obtained. High mutation rates have been described at the blood group B-system locus of cattle, $2 \times 10^{-3}$ (Stormont, 1969), in the lactate dehydrogenase $\mathrm{B}$ subunit in brook trout, $2 \times 10^{-2}$ (Wright and Atherton, 1968), and at the 6-phosphogluconate dehydrogenase locus in Japanese Quail, $1 \times 10^{-2}$ (Ohno et al., 1969). The latter observed mutations from known alleles to previously undescribed variants with slight differences in electrophoretic mobility as well as mutations from one known allele to another as described here. No new variants were observed in any of the experiments in this study.

At the PGM locus three mutations were from a heterozygous parent, one from a homozygote and one from a heterozygote $\times$ homozygote triploid cross in which either parent could have been responsible. The GPI-A mutant was from a homozygous cross. The possibility exists that high mutation rates may arise from intra-cistronic recombination. To date too few crosses at this locus have been tested to draw significant conclusions and further studies are intended.

Linkage was not observed between any two loci, but MDH was not included in the tests nor tests between GPI-A and G3PDH. With a haploid complement of 24 small telocentric chromosomes, the probability of linkage is low amongst four random loci. However, two of the loci were concerned with one enzyme (GPI) and had they arisen by tandem duplication-there is no evidence that pleuronectids are ancient tetraploids-they might have been expected to show close linkage.

The extent of linkage between loci and centromeres was estimated by the production of diploid gynogenetic offspring from heterozygous females. Since diploidy arises by the suppression of the second meiotic metaphase (Purdom, 1969) offspring will be homozygous except where recombination occurred between the centromere and the locus under consideration. One cross-over will produce a heterozygous pair of chromosomes in the egg. Two cross-overs involving only one pair of chromatids will not produce recombination, but where the involvement of chromatids is random, the situation is more complex. The addition of a cross-over to a situation otherwise leading to homozygosity will produce a heterozygote. Of the four possibilities arising when the extra cross-over is applied to a heterozygous situation, two lead to homozygosity and two to heterozygosity. The probability of heterozygosity with $x$ cross-overs is therefore

$$
P_{(x)}=1-\frac{1}{2} P_{(x-1)}
$$


and this will tend towards $0 \cdot 67$. For two of the loci, MDH-A and GPI-B, the frequency of recombination is well below this limit, but for PGM it is significantly higher $(0 \cdot 82$, s.e. $0 \cdot 02)$.

A high level of observed recombination could arise through loss of homozygotes due to lethal or deleterious genes, but at the PGM locus there was no evidence of disparity between the frequencies of the two homozygous classes.

Cross-over interference could also explain the high level of recombination for PGM and several models can be envisaged.

To arrive at minimum estimates of chromosome map length, the simplest assumption is that interference is absolute and only one cross-over permitted per chromosome. On this basis, the three loci studied are approximately 41 units (PGM), 19 units (MDH-A) and 9 units (GPI-B) from the centromere on each of the chromosomes on which they are located. The first two represent high cross-over values for fish. Older studies with aquarium fish (Winge, 1927; Gordon, 1937) report cross-over values up to 10 units, but usually very much less. These data, however, refer to sex-linked loci controlling secondary sexual characters and may not be representative of autosomal situations. Morrison and Wright (1966) report linkage between two lactate dehydrogenase loci in Salvelinus hybrids with recombination of about 15 per cent. Similarly, in segregation analyses using hybrids of Lepomis in which the parents showed differing mobilities for homologous enzymes, Wheat et al. (1973) reported linkage between G3PDH and 6phosphogluconate dehydrogenase with $15-22$ per cent recombination. A high recombination frequency is also suggested between the centromere and the G3PDH locus from a triploid cross in the present series in which four of the six offspring were recombinants. Assuming that the PGM locus is terminal on one of the large chromosomes the total map length of the 24 telocentric chromosomes in plaice (Barker, 1972) in which the largest is about twice the size of the smallest, can be estimated to be about 720 units. Considering that the Pleuronectidae, like most teleosts, have a genome only 20 per cent the size of the mammalian genome (Ohno and Atkins, 1966), this represents a very high total map length and may indicate a very high level of euchromatin.

\section{REFERENCES}

BARKer, c. 1972. A method for the display of chromosomes of plaice, Pleuronectes platessa, and other marine fishes. Copeia, 1972, 365-368.

CHRISTIANSEN, F. B., FRYDENBERG, O., AND SIMONSEN, v. 1973. Genetics of Zoarces populations. IV. Selection component analysis of an esterase polymorphism using population samples including mother-offspring combinations. Hereditas, 73, 291-304.

CLAYTON, J. W., FRANZIN, w. G., AND TRETIAK, D. N. 1973. Genetics of glycerol-3-phosphate dehydrogenase isozymes in white muscle of lake whitefish (Coregonus clupeaformis). $\mathcal{J}$. Fish. Res. Bd Can., 30, 187-193.

CLAYTON, J. W., AND TRETIAK, D. N. 1972. Amine-citrate buffers for pH control in starch gel electrophoresis. F. Fish. Res. Bd Can., 29, 1169-1172.

ClAYTON, J. W., TRETIAK, D. N., AND KOOYMAN, A. H. 1971. Genetics of multiple malate dehydrogenase isozymes in skeletal muscle of walleye (Stizostedion vitreum vitreum). $\mathcal{J}$. Fish. Res. Bd Can., 28, 1005-1008.

DANDO, P. R. 1970. Megrim (Lepidorhombus whiff-iagonis) populations in the English Channel and Approaches-lactate dehydrogenase and glycerol-3-phosphate dehydrogenase polymorphisms. F. mar. biol. Ass. U.K., 40, 801-818.

ENGEL, W., SCHMIDTKE, J., AND WOLF, v. 1971. Genetic variation of $\alpha$-glycero-phosphate dehydrogenase isoenzymes in clupeoid and salmonoid fish. Experientia, 27, 1489-1491. 
FUJINO, K., AND KANG, J. 1968. Transferrin groups of tunas. Genetics, 59, 79-91.

Gordon, M. 1937. Genetics of Platypoecilus. III. Inheritance of sex and crossing-over of the sex chromosomes in the platyfish. Genetics, 22, 376-392.

JoHnson, M. s. 1971. Adaptive lactate dehydrogenase variation in the crested blenny, Anoplarchus. Heredity, 27, 205-226.

коEнN, R. K. 1970. Functional and evolutionary dynamics of polymorphic esterases in catostomid fish. Trans. Am. Fish. Soc., 99, 219-228.

IIGNY, w. DE. 1969. Serological and biochemical studies on fish populations. In H. Barnes (Ed.), Oceanogr. Ė mar. Biol. Ann. Rev. 7, pp. 41 1-513. Allen and Unwin Ltd., London. MERRITT, R. B. 1972. Geographic distribution and enzymatic properties of lactate dehydrogenase allozymes in the fathead minnow, Pimephales promelas. Am. Nat., 106, 173-184.

MORRISON, W. J., AND WRIGHT, J. E. 1966. Genetic analysis of three lactate dehydrogenase isozyme systems in trout: evidence for linkage of genes coding snbunits A and B. 7 . Exp. Biol., 163, 259-270.

NUMACHI, K. 1971. Genetic polymorphism of $\alpha$-glycerophosphate dehydrogenase in saury, Cololabis saira. Seven variant forms and genetic control. Bull. Fap. Soc. Scient. Fish., 37, 755-760.

oHNO, s., AND ATKINS, N. B. 1966. Comparative DNA values and chromosome complements of eight species of fishes. Chromosoma (Berl.), 18, 455-466.

OHNO, s., stenius, c., Christian, L., AND schipmanN, G. 1969. De novo mutation-like events observed at the 6PGD locus in the Japanese Quail, and the principle of polymorphism breeding more polymorphism. Biochem. Genet., 3, 417-428.

POWERS, D. A., AND POWERS, D. 1975. Predicting gene frequencies in natural populations: a testable hypothesis. In Isozymes 4, pp. 63-84, Ed. C. Markert. Academic Press, New York and London.

PuRdom, c. E. 1969. Radiation-induced gynogenesis and androgenesis in fish. Heredity (Lond.), 24, 431-444.

PURDOM, C. E. 1972. Induced polyploidy in plaice (Pleuronectes platessa L.) and its hybrid with the flounder (Platichthys flesus L.). Heredity (Lond.), 29, 11-24.

sImpson, A. C. 1959. The spawning of the plaice (Pleuronectes platessa) in the North Sea. Fishery Invest. (Lond.), Ser. 2, 22 (7), 111 pp.

stormont, c. 1969. Mammalian immunogenetics. In Genetics Today, 3, pp. 716-722. Ed. by S. J. Geerts. Pergamon Press, New York.

WHEAT, T. E., CHILDERS, W. F., MILlER, E. T., AND WHITT, G. s. 1971. Genetic and in vitro molecular hybridization of malate dehydrogenase isozymes in interpacific bass (Micropterus) hybrids. Anim. Blood Grps. biochem. Genet., 2, 3-14.

WhEAT, T. E., WhITT, G. S., AND CHILDERS, W. F. 1972. Linkage relationships between the homologous malate dehydrogenase loci in teleosts. Genetics, 70, 337-340.

WHEAT, T. E., WHITT, G. S., AND CHILDERS, W. F. 1973. Linkage relationships of six enzyme loci in interspecific sunfish hybrids (Genus Lepomis). Genetics, 74, 343-350.

wINGE, o. 1927. The location of eighteen genes in Lebistes reticulatus. 7. Genet., 18, 1-42. WRIGHT, J. E., AND ATHERTON, L. 1968. Genetic control of interallelic recombination at the LDH B locus in brook trout. Genetics, 60, 240. 